\title{
Recruitment Of Hispanic Students Into MIS Curricula
}

Roger McHaney, (E-mail: mchaney@ksu.edu), Kansas State University

Dawne Martin, Kansas State University

\begin{abstract}
This paper provides several suggestions Hispanic student recruitment and retention in MIS or other business curricula. Cultural considerations like allocentrism and familialism are discussed along with the situation at $K$-State.
\end{abstract}

\section{INTRODUCTION}

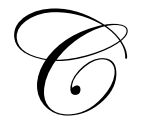

entral Kansas consists of nine counties commonly referred to as the Flint Hills reflecting the rolling tall-grass prairies of the area. Cattle ranching, food processing, and value-added agribusinesses are common in the area. During the past decade, an increased demand for agriculture-related unskilled and semi-skilled jobs has stimulated an influx of new Kansans. These immigrants and their families have added diversity and richness to the region. Recently, call centers, small manufacturing facilities, and other businesses requiring higher skill levels have been attracted to the area. This is partly due to the student labor force reflecting the impact of K-State, a major university located in its midst and to Fort Riley, an Army base which has been dramatically increased in size in the past year. The newer job positions requiring technically skilled people have been more difficult to fill and reflecting national trends, the inability of employers to adequately fill positions have contributed to outsourcing practices.

Between 1997 and 2006, the Hispanic population in the State of Kansas has grown rapidly. During the same time period, the numbers of Hispanic students entering K-State has not reflected the demographic changes in the surrounding population. Numbers for 2005 indicated that there were 595 Hispanic students on campus (counting Mexican-Americans and other Hispanics) from a total of 22,762 students. That represents $2.57 \%$ of the student body. In 2000, according to the U.S. Census, $7 \%$ of the state of Kansas population was Hispanic. Also according to the Census, Hispanic population in Kansas is growing at a rate of about $8 \%$ a year. Thus, the Hispanic population in the state can be estimated at $9.82 \%$ for 2005. Since 1997 the percentage of Hispanic students on campus went from $2.20 \%$ to $2.57 \%$, a growth rate of about $2 \%$ a year. If K-State had a percentage of Hispanic students consistent with Kansas population, approximately 2,275 Hispanic students would be enrolled on campus. Even if the percentage of Hispanic students remained consistent with K-State demographic trends since 2001, over 700 Hispanic students would be enrolled now, but only 535 are on campus. If K-State and the State of Kansas keep their current trend, by the end of this decade Hispanics account for more than 12\% of Kansas' population but only $2.59 \%$ of K-State's enrollment (Alianza, 2004; Planning and Analysis, 2005).

In other related statistics, the Non-Hispanic White population in Kansas was $83.3 \%$ in April 2000 according to the Census. The Census Bureau estimate for July 2003 is that Non-Hispanic White population in Kansas was at $81.9 \%$ (U.S. Census Bureau, 2004). With the current trend, over $22 \%$ of Kansas population will be non-white by the end of this decade. It is highly plausible that just 15 years from now one in three Kansas residents and about half of the high school population will be of minority background.

This disparity reflects a trend that unless reversed, could easily result in a disenfranchised subculture with latent talents not being effectively deployed in society. If population growth is compared using the 1990 and the 2000 U.S. Census, the population in Kansas grew 8.3\%, but that the Non-Hispanic White population in Kansas 
remained constant. This means that growth in minority population accounts for almost $100 \%$ of the population growth in the state (adapted from Alianza, 2004).

In addition to these discouraging statistics, the percent of Hispanic students in IT-related curricula at KState is dismal. In 2005, out of 18,067 undergraduate K-State students, only 11 Hispanics were in specific computerrelated curricula. This compares to an overall headcount of 577 students enrolled in specific computer-related curricula. A total of $3.2 \%$ of all K-State undergraduate students are in computer-related curriculum but only $2 \%$ of Hispanic students are in computer-related curricula. If the percent of Hispanic students enrolled in technology programs were equivalent to the percent of Hispanics in the general Kansas population, we would expect to see 56 students enrolled instead of 11. Even if the percent of Hispanic students in computer-related curricula were proportional to the number of Hispanics on campus, we could expect to have nearly 19 enrolled.

Another problem area is retention of Hispanic students. K-State was $12^{\text {th }}$ in the big twelve for graduation rate $(33 \%)$ of Hispanic students according to a study published in 2002 by Black Issues in Higher Education. KState's most recent data for 6-year graduation of Hispanic students is $40.28 \%$, an improvement, but very low compared with the general average of 53\%, and an average of over $60 \%$ for white students (adapted from Alianza, 2004).

\section{REVERSING THE TREND}

By leveraging demographic changes within the state of Kansas and other central plains states, these trends might be reversed in a manner favorable to the local economy. Effective university recruitment and retention issues are considered to be part of a more comprehensive solution. A discussion follows.

\section{EFFECTIVE RECRUITMENT OF HISPANIC STUDENTS FOR IT-RELATED CURRICULA}

Any effective recruitment process begins with a plan that considers the target audience together with its demographics, values, and general level of education (Torres-Davis, 1994). More so than in other societies, this plan must consider the importance that cultural issues play in the lives of Hispanic students (Walker \& Schultz, 2000/2001). According to many researchers (Henderson \& Berla, 1994; Griggs \& Dunn, 1996; and Fisher et. al. 2004), family involvement is a key factor in Hispanic educational achievement and persistence. Without the support of his or her family, a Hispanic student, more so than students from other cultural backgrounds, is less likely to engage or successfully complete an educational program. In addition to family involvement, other cultural values salient to Hispanic society must be integrated as program building blocks to ensure success. Marín \& Marín (1991) identified seven intrinsic Hispanic cultural values that are central to the recruitment and retention. These values are summarized in Table 1.

Table 1: Hispanic Cultural Values from Marín \& Marín (1991)

\begin{tabular}{|c|l|}
\hline Hispanic Cultural Value & \multicolumn{1}{c|}{ Description } \\
\hline Allocentrism & $\begin{array}{l}\text { Societies that emphasize the needs, objectives, and points of view of someone belonging to the } \\
\text { group. Individualism, as emphasized by non-minority groups in the U.S., is less important. }\end{array}$ \\
\hline Familialism & $\begin{array}{l}\text { The strong attachment of an individual to both nuclear and extended families. This is considered } \\
\text { one of the most important Hispanic cultural values. }\end{array}$ \\
\hline Gender Roles & Hispanic societies have very strongly defined gender roles for both males and females. \\
\hline Power Distance & $\begin{array}{l}\text { Power distance is the measure of interpersonal power that exists between two individuals. This } \\
\text { means that conformity and obedience are valued. It also means that autocratic and authoritarian } \\
\text { attitudes from those in charge of organizations are generally supported. }\end{array}$ \\
\hline Personal Space & $\begin{array}{l}\text { Contact cultures are more likely to feel comfortable when physically close to others. They are } \\
\text { also less likely to feel personal space has been invaded when a stranger comes close to them. }\end{array}$ \\
\hline Simpatía & $\begin{array}{l}\text { This cultural trait emphasizes the need for behaviors that promote smooth and pleasant social } \\
\text { relationships. People with simpatía tend to behave with respect and dignity in order to promote } \\
\text { harmony and avoid pointing out the failures and embarrassments of others. }\end{array}$ \\
\hline Time Orientation & $\begin{array}{l}\text { Individuals in Hispanic cultures tend to place more emphasis on the quality of personal } \\
\text { relationships and not the length of time over which they take place. }\end{array}$ \\
\hline
\end{tabular}


During recruitment, it is still important to recognize the Hispanic population is comprised of individuals and while certain similarities within the group exist, variations will be present. As suggested by Torres-Davis (1994), it is important to safeguard against the perpetuation of stereotypes.

\section{RETENTION OF HISPANIC STUDENTS}

Retention is considered successful when Hispanic students remain in Kansas State University's computingrelated curricula and ultimately enter the IT-related workforce. Cultural values play an even more important role in the retention of Hispanic students than in the initial recruitment efforts. In a 1993 study, Solberg reported that three factors contributed to Hispanic students leaving higher education: (1) academic stress coupled with no support system; (2) social stress resulting from being away from family and lack a sense of community; and (3) financial stress.

Successful retention will address all of these areas specifically to mitigate the potential effects reported by Solberg (1993). First, the program must consider mechanisms for easing academic stress. This might be accomplished through familiarization with on-campus Hispanic organizations. At K-State, this includes the Hispanic student group HALO and the Alianza organization. It also could include the use of a mentoring system comprised of K-State faculty, local members of the Hispanic business community, and other students. This can help provide a surrogate sense of allocentrism. The second stressor, lack of family connectedness can be minimized in the same way. Familialism issues can be reduced through mentoring and social programs. In addition, connection to the family can be maintained using virtual communication methods such as desktop videoconferencing, chat rooms, and blogs. The third stressor, financial stress must also be addressed. Both scholarships and work-related opportunities on campus and in the surrounding community can help.

\section{CONCLUSION}

In conclusion, it is believed that the recruitment and retention of Hispanic students can be influenced positively by considering cultural issues such as those suggested by Marín \& Marín (1991). Development of a more diverse student population and leveraging latent capability in the local population of new Kansans potentially will strengthen the local economy and help pave the way for a better future in the Midwest.

\section{REFERENCES}

1. Alianza, (2004). Situation of Hispanics on Campus--Informal Diagnosis 2004. Retrieved September 1, 2006, from K-State Alianza Web site: http://www.k-state.edu/alianza/intro/ksulatinos.htm.

2. Fisher, Karen E., Marcoux, Elizabeth (Betty), Miller, Lupine S., Sanchez, Agueda, \& Cunningham, Eva Ramirez (2004). Information behaviour of migrant Hispanic farm workers and their families in the Pacific Northwest. Information Research 10 (1).

3. Griggs, S., \& Dunn, R. (1996). Hispanic-American students and learning styles. Urbana, IL: ERIC Clearinghouse on Elementary and Early Childhood Education. (ERIC Document Reproduction Service, NO. ED 393 607).

4. Henderson, A.T., \& Berla, N. (Eds.) (1994). A new generation of evidence: The family is critical to student achievement. Washington, DC: National Committee for Citizens in Education.

5. Marin, G., \& Marin, B. V. (1991). Research with Hispanic populations. Newbury Park, CA: Sage Publications

6. Planning and Analysis, (2005). Statistics \& Historical Data. Retrieved September 1, 2006, Web site: http://www.k-state.edu/pa/statinfo/index.htm

7. Solberg, V. S. (1993). Development of the College Stress Inventory for use with Hispanic populations: A confirmatory analytic approach. Hispanic Journal of Behavioral Sciences, 15(4), 490-497.

8. Torres-Davis, Ana (1994). Developing a Hispanic Outreach Program That Works. The A.T. Quarterly 5(1).

9. U.S. Census Bureau, (September 29, 2004). Population estimates by state. Retrieved September 1, 2006, from Population Estimates Web site: http://www.census.gov/popest/states/asrh/SC-EST2003-03.html 
10. Walker, D. A, A M Schultz, (2000-2001), Reaching for Diversity: Recruiting and Retaining MexicanAmerican Students, Journal of College Student Retention 2(4), pp. 313-25.

\section{NOTES}

